\title{
Civil Society, Health, and Social Exclusion in Bangladesh
}

\author{
Anna T. Schurmann' and Simeen Mahmud ${ }^{2}$ \\ 'University of North Carolina, Chapel Hill, USA and 'Bangladesh Institute of \\ Development Studies, Dhaka, Bangladesh
}

\begin{abstract}
Civil society has the potential to have a positive impact on social exclusion and health equity through active monitoring and increased accountability. This paper examines the role of civil society in Bangladesh to understand why this potential has not been realized. Looking at two models of civil society actionparticipation in decentralized public-sector service provision and academic think-tank data analysis-this analysis examines the barriers to positive civil society input into public policy decision-making. The role of non-governmental organizations, political, cultural and economic factors, and the influence of foreign bilateral and multilateral donors are considered. The paper concludes that, with a few exceptions, civil society in Bangladesh replicates the structural inequalities of society at large.
\end{abstract}

Key words: Civil society; Health equity; Health systems; Participation; Social exclusion; Bangladesh

\section{INTRODUCTION}

Civil society is a potential mechanism to refocus healthcare systems according to health rights and social welfare goals through mobilization of citizen demand for accountability and relevant service provision (1). The right to health is generally perceived as the state's obligation to deliver affordable, accessible health services to all and is enshrined in Article 12 of the International Covenant on Economic, Social and Cultural Rights $(2,3)$. The movement for people's participation in health is marked by the 1978 Alma-Ata declaration, which called for people's participation in local health systems and their active involvement in defining priorities for scarce resources (4). The World Bank, which promoted participation in all sectors with goals of decentralization and cost-cutting, further propelled this trend in the mid-1990s. Community participation is now widely expected to ensure that health systems are relevant, efficient, and sustainable, while public pressure is expected to improve quality, reduce inequity, and prevent corruption (2).

Correspondence and reprint requests should be addressed to:

Anna T. Schurmann

Carolina Population Center

University of North Carolina

CB 8120

Chapel Hill, NC, 27516

USA

Email: annaschurmann@unc.edu
This analysis reviews the literature on civil society in Bangladesh. We briefly discuss the need for civil society's involvement in championing health equity and present the conflicting role of non-governmental organizations (NGOs) in promoting health equity. We recount examples of large-scale efforts to engage civil society in raising the quality of healthcare. These examples follow two main paths. First, an increased emphasis on decentralization as a means of localizing policy-making, bringing decision-making closer to disadvantaged groups, and encouraging local participation. A second mechanism is academic and professional monitoring and analysis. Although such professionals are unlikely to be members of the poor or excluded, they may speak on their behalf. Data produced may suggest ways in which health resources could be equitably distributed, correcting the elite capture often implicit in participatory decision-making. This analysis will examine examples of both of these intervention mechanisms as they have occurred in Bangladesh in relation to health. In the subsequent section, social exclusion theory provides a useful framework for revealing the complex economic, social, and political challenges to the success of civil society in holding the Government accountable.

\section{BACKGROUND}

Civil society in Bangladesh

Civil society is currently being emphasized as cen- 
tral to the development process (5-7). Civil society is a broad concept that includes all voluntary organizations and associations that exist in the realm between, and are independent from, the state and the family $(7,8)$. Mosque congregations, labour unions, professional associations, and NGOs are all factions of civil society, groups advocating for 'public interest' or at least to extend their own interests and values. Public interest is naturally a highly contested domain, and the essential heterogeneity of civil society means that there will often be contrary factions. For example, labour unions and the business community may hold different opinions about which policies are likely to contribute to the greater good but both are important contributors to a rich civil society. Still, the impact and meaning of an active and diverse civil society is under debate. Robert Putnam argues that weak civil society leads to a lack of civic engagement and social trust. However, active civil society can also be an indicator of state or political weaknesses (7).

Civil society's potential for positive change is theorized to occur by increasing social associations (contacts), trust, and increasing engagement with governance infrastructure to ensure that people's voices are heard and needs met. Ideally, civil society organizations (CSOs) provide transparency and accountability of government services through peoples' active scrutiny, advocacy, and monitoring to make service providers more responsive to the perceived needs of communities (9). Compared to state entities, CSO's smaller bureaucracy provides them with more agility and an independent, critical space to play a stronger watchdog role. People's direct participation in state functioning, through such civil society activities, ideally ensures that service-delivery is relevant and efficient. In this manner, civil society can act as a mechanism to complement and augment state functioning, bridging gaps between service providers and communities (10). As Bangura says, "If the public sector is to function effectively and enjoy widespread legitimacy, all groups in society must feel a sense of belonging, representation and shared interest in the institutions that govern their lives" $(11,12)$. The Health, Nutrition and Population Sector Plan (HNPSP) 2003-2010 of the Ministry of Health and Family Welfare, Government of Bangladesh, also notes that civil society should "advocate and support the needs of the consumers" (13). However, civil society in Bangladesh has not played this role.

Defining civil society in Bangladesh: role of NGOs Civil society is clearly locally specific, reflecting the economic, social, and political context. Civil society in Bangladesh has been shaped by a rich history from the struggle for independence against the British (1947) and then Pakistan (1971), the language movement (1952), and the movement for democracy (1991) to the communal efforts at flood reconstruction $(1988,1998,2004)$ (14). However, to begin to define Bangladeshi civil society, the unique role played by NGOs must first be clarified. NGOs play an ambiguous role because their role often overlaps with the Government's in terms of public service provision, and they often engage in market-based activities; so, they do not consistently play a civil society role $(6,7,15)$. That is, they are not consistently able to play the role of independent monitor and advocate. It should be noted that other institutional and operational definitions of civil society gloss over these contradictions and include service provision as a non-problematic role for civil society $(16,17)$.

More importantly, although less common in Bangladesh, NGOs play a critical role in building capacity through social mobilization efforts and creating effective civil society actors.

NGOs in Bangladesh emerged through the mobilization for reconstruction in the aftermath of the War of Liberation in 1971 and the famine in 1974 , in the absence of a functioning state. Today, Bangladesh has thousands of NGOs, including advocacy groups and service organizations at the national and local levels. A recent count reported 22,000 , with approximately 1,250 receiving foreign funding. Seventy-eight percent of the villages in Bangladesh benefit from the presence of at least one NGO, and $35 \%$ of the population is directly provided with NGO services-either credit, education, health or sanitation services (18). Why have NGOs flourished in Bangladesh? Davis (2001) cites weak state service provision, low levels of private foreign investment, and high levels of readily available bilateral and multilateral donor funding as the principal factors that created the political and economic space for such organizations. The end result is a 'franchise state' where essential public services are run by NGOs funded by donors or the state $(18,20)$.

It must be highlighted that the Bangladeshi NGOs that provide services are meeting urgent needs and generally doing an excellent job. Many of Bangladesh's development success stories, such as the microcredit and non-formal education, originated with NGOs (8). For example, Building Resources Across Communities (BRAC) has become one of 
the country's principal providers of health, education, and credit in poor rural areas (19). Their innovations have been replicated in other developing countries throughout the world (for example, the Grameen Foundation, a US-based charity which replicates the work of the Grameen Bank in other developing countries).

When compared to equivalent government operations, NGO services generally run more efficiently and cheaply, with closer ties to communities. For this reason, donors often favour them as entry points to accessing communities in Bangladesh, especially since the 1980s (20). Often, NGOs run government projects for the Government itself. Indeed, as White points out, in the eyes of many villagers, NGO personnel are indistinguishable from government personnel; they are similarly part of 'officialdom' (21).

The effect of NGO service provision can operate in two ways: NGOs can raise the bar and, through competition, improve government service provision; or NGO provision can become a substitute for government provision, thereby reducing the demand for quality government services, causing government services to falter, their legitimacy undermined $(22,23)$. Although a small number of NGOs devote themselves entirely to rights-based agenda, such as Nijera Kori and Samata, most NGOs in Bangladesh balance their advocacy role with service-delivery, the most influential example being BRAC (8). There are others that are only service providers.

However, the role of service provision can distract NGOs from another important role-that of advocate and independent monitor of government activity. As service providers, they are less able to facilitate input of citizens into the policy process or hold the state accountable for its misdeeds and corruptions $(6,15,23)$. This means that both NGO and government service providers are then spared from independent monitoring and accountability. All too often, in an effort to bolster successes and improve project reporting, the relatively easy-to-assist marginally poor are targeted at the expense of the ultra-poor $(8,10)$.

Inequity in health-sector spending

Civil society is suggested as a panacea for a wide range of ills; however, this paper is particularly concerned with engagement of civil society in the health system. In Bangladesh, typical of many parts of the world, health resources are distributed ineq- uitably with a strong elite bias. A global analysis that included Bangladesh found that the wealthiest $20 \%$ of the population received over $26 \%$ of total financial subsidies provided by government health expenditure compared to the poorest $20 \%$ of the population who received only $16 \%$ (19). More specifically, in Bangladesh, the expenditure of the Ministry of Health and Family Welfare is almost equally divided among the poor and nonpoor. However, large expenditure for health by other ministries, such as the Ministry of Defense (on hospitals and clinics), skews spending towards rich and urban areas. Public expenditure for health is about equal for males and females but private expenditure greatly favours men. Furthermore, rural residents (approximately 80\% of the population) receive less than half the public spending on health, and only $12 \%$ of the rural population have access to public health at all (20). High levels of doctor absenteeism in rural areas and illegal userfees, which inordinately affect the poor and exacerbate the situation. Furthermore, negligence and unprofessional behaviour by service providers, poor maintenance of physical facilities, 'leakages' of resources, and long waiting-times plague provision of general health services. While there have been internal systems in place to ensure quality of care and accountability, they have been largely non-functional (2).

Despite attempts at health sector reform, citizens' perceptions and usage of the system have declined. Between 1999 and 2003, public rating of government health services as 'good' fell from 37\% to $10 \%$; and the proportion of patients accessing government services fell from $13 \%$ to $10 \%$, while unmet need increased from $3 \%$ to $9 \%$ (24).

\section{EXAMPLES OF ENGAGEMENT OF CIVIL SOCIETY IN HEALTH}

The following three case studies provide examples of recent attempts to encourage civil society activity to increase accountability of the public health sector in Bangladesh, according to different models. All three reveal different potentialities and barriers to participation of civil society, illustrating the complexity of the concept and its application in this unique political and social context. The first two cases, on stakeholder committees and village community groups, are based on earlier work by Mahmud (2,25). The last one, on more formal monitoring organizations, was researched by examining the documentation and reports from Health Watch and Bangladesh Health Equity Watch. 
Case study I: Stakeholder Committees, 1998-2003

The Government of Bangladesh's five-year plan -the Health and Population Sector Programme 1998-2003-highlighted the importance of stakeholder consultation and participation. The Ministry of Health and Family Welfare established stakeholder committees of local resident service users to monitor the performance of public service providers at the local level. The ministry used NGOs for this purpose as they are well-networked at the community level. Nijera Kori, an NGO created in the 1980s, has a long history of social mobilization and was asked to set up local meetings in different parts of the country to provide poor people with an opportunity to provide input into how these groups might work. Eventually, Nijera Kori, Voluntary Health Service Society, BRAC, and Mahila Parishad (four different NGOs) were given the task of forming community-level stakeholder committees with community representatives in nine districts on an experimental basis.

The guidelines of the Government for group membership emphasized that members should come from different professional and social groups. The Nijera Kori groups were more specific: 50\% of membership were women, two members were from landless groups, two professionals, one teacher and one service-delivery person, a union parishad member, and two representatives from the union stakeholder committees. At the community's behest, doctors and medical staff were excluded from membership to ensure no conflict of interest, although they were occasionally invited to meetings. The recruitment process was reported to be transparent and participatory (2).

Nijera Kori provided training to its members in participation and deliberation and also provided institutional support when problems or hostilities with doctors arose. Possibly due to this capacitybuilding, meetings for the stakeholder committees were structured and productive, and members participated more or less equally, although in different ways. For example, 'elite' members appeared to be more comfortable discussing and debating points while the poorer members were more willing to mobilize and protest (2).

Despite the success in establishing dialogue, the stakeholder committees lacked authority or political clout to enact decisions, and they were given little official recognition. General community awareness about the committees and the opportunity it afforded to channel complaints and feedback about the healthcare system was low (2). However, the stakeholder committees had a positive impact on communities, including raising awareness about health facilities, and increasing community demand, putting pressure on doctors to arrive on time and stop levying illegal fees on patients. The new health policy launched in 2005 had no provision for supporting the stakeholder committees, and all those, except the ones run by Nijera Kori, were disbanded.

\section{Case study 2: Village Community Groups}

As with case study 1 , as part of the Health and Population Sector Programme 1998-2003, the Ministry of Health and Family Welfare decided to set up community-owned and managed primary health clinics in every village. These clinics delivered an 'essential services package' that merged reproductive and primary health, which were previously separate programmes delivered through homevisits (26). Community 'ownership' was attempted by a requirement that the community donate the land for the health centre and share the cost of construction with the Government. The Government provided salaries for the health workers. Clinic maintenance, such as cleaning and security, was to be provided by the community. In all, 10,000 clinics were established (27).

The elected Union Parishad Chairman, through local consultation, recruited members of the Village Community Groups that would manage these centres. Unlike the stakeholder committees in the previous case study, the medical profession was represented in the groups. Unfortunately, the selection process was vulnerable to elite capture; membership was biased towards the better-off community members, limiting its acceptability to the wider community. Group members were often the relatives or close associates of the District Council Chairman. Understanding of the roles of group members was limited, even among group members themselves.

Leadership and meeting structure was poor, and subsequently, little was achieved. In the absence of proper structure, structural inequalities were reproduced in group functioning. As a result, women and the poor were given little opportunity to contribute to discussion. Groups were given little official support or credibility from the local upazila, undermining any decisions that were made. The groups were generally unwilling or unable to mobilize resources, leading to deterioration in infra- 
structure. Clinics were generally in disrepair with broken tubewells and leaking roofs. Supplies were always inadequate. By 2001, all 10,000 clinics had fallen into disuse $(2,27)$.

These models (case study 1 and 2) have been superseded by the Health, Nutrition, and Population Sector Programme with Health Services User's Fora; however, there are no data yet about their functioning (13).

\section{Case study 3: Bangladesh Health Equity Watch and Health Watch}

Aside from efforts to include communities in policy decision-making, civil society can also provide a professional oversight and monitoring function. In this case, emphasis is placed not on ensuring locally relevant and inclusive decision-making but instead the injection of expert data collection and critical analysis into the policy process. This function is undertaken by academics, think-tanks, and NGOs with significant technical capacity. In the field of health, two such groups have emerged: Health Watch and Bangladesh Health Equity Watch.

Bangladesh Health Equity Watch (BHEW) emerged out of a global initiative-Global Health Equity Initiative-that started in Chile in 1999. In Bangladesh, it is coordinated by the Bangladesh Bureau of Statistics, the Bangladesh Institute of Development Studies, BRAC, and ICDDR,B. the BHEW conducts a national survey of health equity, analyzes existing data with an equity focus, plays a strong advocacy function, and builds capacity in survey research. In 2005, in a similar gesture, with the same key players, a number of professional and civil society groups came together to create a network that would regularly and systematically measure the performance of Bangladesh in terms of health to both inform policy and raise general awareness. Bangladesh Health Watch, housed at the BRAC School of Public Health, publishes a report every year focusing on specific themes and regularly reports on key indicators. The first report, published in 2006, addressed the theme of health and equity. Bangladesh Health Watch is governed by an advisory board consisting of key people in the field of development and health. A working group carries out the different activities of the Watch.

Thus far, the impact of BHEW activities is limited to raising awareness about the extent of inequalities and incorporation of an equity dimension in data collection, analysis, and reporting. The impact of such advocacy interventions can be difficult to measure. While such advocacy does not incorporate the participation of those in need, data-based decision-making may provide a corrective to the elite capture often present in attempts to incorporate civil society input into policy dialogue and may ensure that government decision-making addresses those most in need.

\section{SOCIAL EXCLUSION ANALYSIS}

What curbs the effectiveness of civil society in creating equity in Bangladesh, as in the case studies above? Social exclusion theory provides a framework for understanding the challenges in the functioning of civil society (28). The factors examined here are poverty, political capacity, patron-client relationships, political exclusion, and involvement of donors. The factors have been determined through deduction from the literature and analysis of the above case studies. While these factors are described in isolation, they operate hand-in-hand to exclude certain populations from equal participation.

\section{Economic exclusion: situation of the poor}

Poverty poses a significant challenge to citizen agency in Bangladesh. Poverty usually comes as a package deal: translating not only to mean lack of income but also lack of capabilities through lack of education, compromised health, and other factors. Poor people often have to work hard over long hours and may have little time for participating in activities that do not directly contribute to their livelihood-especially when the gains are often intangible and in the distant future. Participation in organized efforts of civil society involves the opportunity cost of productive work (23). Furthermore, poor people in Bangladesh are also often made invisible and conduct their lives in informal spaces relating to their livelihood pursuits, such as savings groups and village factions (2). They do not have access to formal spaces where their voices can be heard by policy-makers and do not have the institutional literacy to navigate such spaces. The poor are also very vulnerable, and the threat of withdrawal of patron support is real, limiting the opportunities for poor people to participate in the activity of civil society. Poor people often see themselves as having little responsibility or capability for creation of a 'good society' (2). As in the case studies above, without careful capacity-building and clear guidelines, such as provided by Nijera Kori, the poor were sidelined in participatory governance measures. 


\section{Political capacity}

Activity of civil society requires appropriate skills on the part of the populace, CSOs, and the state. High levels of poverty and the concomitant low levels of education may limit capacity and confidence to challenge state actions, since the poor have limited knowledge of delivery mechanisms and are unable to effectively assess technical aspects of service operations. The ability to critically engage with the state requires a level of institutional literacy that many poor people in Bangladesh do not have. One of the main barriers is lack of education, or literacy, to enable people to feel comfortable with, and critical of, modern institutions, such as the formal healthcare system. Education Watch 2002 found that 41\% of people aged over 11 years were literate; in addition, 37\% of people in Bangladesh remain illiterate or semiliterate after completing five years of primary education. Illiteracy clearly indicates a lack of capacity on the part of the populace to participate in ventures of civil society, according to the traditional definition (29). The prejudices surrounding illiteracy and poverty mean that policy-makers presume that the poor are unaware of their health needs and are best guided by the opinion of experts (30).

To incorporate local perspectives into healthcare requires institutional change to enable service providers to build relationships and trust, listen, and respond to the needs of the community $(11,22,31)$, such as was provided by Nijera Kori in the case studies above.

\section{Client-patron relationships}

Another significant barrier to engagement of civil society in health systems is the client-patron relationships that structure the social fabric of patrimonial countries like Bangladesh. People in Bangladesh have traditionally relied on vertical patron-client relationships for social protection (32). Such relationships leave the vast majority of the population at subsistence levels and a large minority in sub-poverty while providing unearned income, rent and/or power to patrons. The destitute, or the ultra-poor, are generally excluded from such relationships. In such a system, welfare of the people depends on the whim of the patron rather than any outside or objective standard; clients are rendered as passive beneficiaries of patron 'favours' rather than as citizens with rights (8). Funds allocated for the development of communities are often squandered by politicians or bureaucrat patrons on maintaining such relation- ships, hindering equitable human and economic development (8). This explains why the BHEW has little policy-impact; resources are distributed to vote banks, not according to needs established through epidemiological and demographic data. It also demonstrates why Village Community Groups are unlikely to be representative-positions are given as patron favours.

White (1999) argues that NGOs themselves have difficulty avoiding the role of 'patron' (21). NGOs are seen as sources of protection and a link to the wider world, for example, through the distribution of relief goods during floods.

Why are these relationships so resilient? There is a common belief in Bangladesh that not everyone has equal rights; and, concomitantly, denial of rights is accepted as the natural order of things (2). This system is also supported by the absence of dependable formal institutions; instead, people have to continue to rely on their patrons and benefactors. The risk-averse poor (clients) are unlikely to violate such bonds and, thus, maintain a high level of loyalty to their patrons. Such relationships are further enabled by a general lack of accountability or transparency with clients having no redress or means to press the state into meeting its obligations. This hinders individual agency and action (2). State responsiveness is directed to patrons only, not the poor.

\section{Political exclusion}

At the national level, the policy environment of Bangladesh is exemplified by the centrality of government officials - the policy elite-and is generally closed to other actors. The NGO Affairs Bureau (NGOAB) closely controls NGO activity and discourages the formation of interest groups. Government repression and NGOAB's regulation of donor funds have been used for keeping NGO policy in check and specifically to prevent NGOs from engaging in any political activity (18). Political activity is frequently conflated with partisan support for opposition parties. Oppositional civil society is seen as a threat to the state, and subsequently, policy elites have either co-opted or excluded civil society actors. In 2004, a large NGO_-Proshika-was shut down by the Government because they had mobilized the poor into pressuring the Government for policy change. Leaders of Proshika were charged with sedition and corruption (18). In such an institutional environment, organized interest groups exist primarily only among the urban elite, and their capacity to impact the policy process is limited (33). 
At the local level, Bangladesh's most proximate form of government is the union parishad-and this is the level of government that impacts most directly on people's lives. A recent World Bank report noted that: "there is a great physical and psychological distance between the lowest administrative level where professional government services are found and the village communities where the need exists" (1). Little precise data are available on the extent to which this form of government is actually accessed. However, this is a very important question. The proximity people 'feel' to their government representative reflects the likelihood of political and civil society's action. As case study 1 demonstrates, political exclusion is compounded when participatory decision-making processes and outcomes are ignored. However, if people feel that their political representative is responsive to the needs of a community, they are more likely to seek positive change. This point is supported by research from rural North India, which suggests that civil society and a responsive political infrastructure are synergistic, each augments the other (12). Political exclusion and health are an important area for further analysis in the context of Bangladesh.

\section{Accountability to external parties}

Donors have a strong role in the health sector in Bangladesh and have done so since independence. Bangladesh receives approximately US $\$ 2$ billion per year in aid, $15 \%$ of which is channeled through NGOs. Since 1998, the World Bank has dominated a consortium of multilateral and bilateral donors in leading sector-wide reforms, such as the Health and Population Sector Policy 1998-2003 and the Health, Nutrition and Population Sector Policy 2005-2010. There are 31 bilateral and multilateral organizations supporting the activities of the Ministry of Health and Family Welfare, providing approximately $35 \%$ of expenditure (34). The many players with their own agenda and reporting requirements can lead to local priorities being subsumed. With donors, rather than tax-payers, providing such a large portion of revenue in the health sector, accountability shifts from the citizen to the donor community $(1,8)$. The strength and number of external actors means that there is no mechanism or leverage for civil society or citizenry to enforce accountability according to their own priorities and values (30). This undermines any ability to catalyze genuine social mobilization or change power structures (20). Health sector decisions are then made outside the domestic political system (20). This situation reflects and augments a significant disconnection between the policy-making process and the populace.

\section{DISCUSSION}

The social exclusion analysis attempts to shed light on why efforts of civil society in health systems failed to effect any positive change in health equity in Bangladesh. The factors highlighted (poverty, political capacity, patron-client relationships, political exclusion, and involvement of donors) do not just preclude civil society activity but also undermine the health system itself. For example, patron-client relationships determine access to affordable, quality care for the poor (26). The factors described are both part of the problem and prevent a potential solution.

The first two case studies demonstrate the structural inequities, which are part of Bangladeshi society and are, therefore, easily reproduced by and within civil society ventures. This is also demonstrated by the co-existence of a large number of NGOs, a strong heritage of civil society activity (14) and chronic inequalities and poverty (15).

This paper suggests that NGO service provision, while important, compromises the role as advocate and monitor and precludes accountability. Despite the constraints in playing a strong civil society role, some NGOs have played an important function through social mobilization efforts as demonstrated by Nijera Kori in case study 1 . Through their efforts, NGOs can provide a space to build social capitalrelationships and networks beyond kin patrons or faction. Such networks can build capacity, generate knowledge, provide information, and empower the marginalized (35). For example, microcredit initiatives bring women together, and this has an effect on individual lives, society, and institutions. This building of social and community capacity may help create civil society actors and an environment in which these actors can hold the state or NGO service providers accountable. This kind of mobilization may counter social exclusion.

The benefits of an informed and inclusive participation can go beyond an improved health system and promote active citizenship. That is, active civil society within one sector will likely benefit other sectors as well. Amartya Sen argues that a politicallyengaged citizenry provokes government to respond more forcefully to underdevelopment and poverty (36). Research from rural North India suggests that social capital is associated with higher levels of political activity, stronger economic development, 
and a higher level of community harmony (12).

\section{Conclusion}

While civil society has potential to positively affect health equity in Bangladesh, there are many factors that curb its ability to affect change and be inclusive. After the social exclusion analysis of the case studies, it is difficult to conclude that civil society activity is a likely determinant of health equity. The case studies demonstrate that weak capacity, complex internal politics, unclear official status, intermittent funding, and general lack of awareness all undermine participatory civil society-based efforts in health. The community groups were unable to address structural factors that cause poor health and inequality, indeed traditional power structures were often reproduced. Barriers were also put in place by the medical establishment and policymakers, who were unwilling or unable to respond to directives and data provided. The case studies suggest that civic cooperation is likely to increase if only supported by state infrastructure, and if efforts are invested in building capacity with both community members (as demonstrated by Nijera Kori in case study 1) and state bureaucracy.

\section{ACKNOWLEDGEMENTS}

This work was made possible through funding provided by the World Health Organization (WHO) and undertaken as work for the Social Exclusion Knowledge Network established as part of the WHO Commission on the Social Determinants of Health. The views presented in this work are those of the authors and do not necessarily represent the decisions, policy or views of WHO or Commissioners.

The authors thank the following people for review and feedback on earlier versions of this paper: Verne Kemerer, Heidi Johnston, Shelley Golden, Anne Martin Staple, Abbas Bhuiya, and Aniruddh Krishna.

\section{REFERENCES}

1. Kapoor K. Taming leviathan: reforming governance in Bangladesh: an institutional review. Washington, DC: World Bank, 2002. 153 p.

2. Mahmud S. Citizen participation in the health sector in rural Bangladesh: perceptions and reality. IDS Bull 2004;35(2):11-8.

3. United Nations. The right to the highest attainable standard of health (Article 12 of the International Covenant on Economic, Social and Cultural Rights). New York, NY: United Nations Economic and Social Council, 2000.
4. Rifkin SB. A framework for linking community empowerment and health equity: it is a matter of CHOICE. J Health Popul Nutr 2003;21:168-80.

5. Lewis D. On the difficulty of studying 'civil society': reflections on NGOs, state and democracy in Bangladesh. Contribut Indian Sociol 2004;38:299-322.

6. Feldman S. Paradoxes of institutionalism: the depoliticisation of Bangladeshi NGOs. Dev Pract 2003;13:526.

7. Carothers T. Think again: civil society. Foreign Policy 1999-2000;(Winter):18-29.

8. Blair H. Civil society and pro-poor initiatives in rural Bangladesh: finding a workable strategy. World Dev 2005;33:921-36.

9. Lerberghe WV, Ferrinhoe P. Civil society and the poor: the unfulfilled expectations. Washington, DC: World Bank, 2002. 43 p.

10. Doyle C, Patel P. Civil Society organizations and global health initiatives: problems of legitimacy. Soc Sci Med 2008;66:1928-38.

11. Kabeer N. Social exclusion and the MDGs: the challenge of 'durable inequalities' in the Asian context. IDS Bull 2006;37(3):64-78.

12. Krishna A. Active social capital: tracing the roots of development and democracy. New York, NY: Columbia University Press, 2002. 252 p.

13. Bangladesh. Ministry of Health and Family Welfare. Health Nutrition Population Sector Policy (HNPSP) 2003-2010; revised program implementation plan. Dhaka: Ministry of Health and Family Welfare, Government of Bangladesh, 2005.

14. Zafaraullah HM, Rahman MH. Human rights, civil society and non-governmental organizations: the nexus in Bangladesh. Hum Rights Q 2002;24:101134.

15. Davis P, McGregor A. Civil society, international donors and poverty in Bangladesh. Commonwealth Compar Polit 2000;38:47-64.

16. Salamon LM, Wojciech Sokolowski SW, List R. Global civil society: an overview. Baltimore, MD: Institute for Policy Studies, Center for Civil Society Studies, Johns Hopkins University, 2003. 64 p.

17. United Nations. Handbook on non-profit institutions in the system of national accounts. New York, NY: Department of Economic and Social Affairs, Statistics Division, United Nations, 2003. 327 p.

18. Rahman S. Development, democracy and the NGO sector: theory and evidence from Bangladesh. J Dev Soc 2006;22:451-73.

19. Gwatkin DR, Bhuiya A, Victora CG. Making health systems more equitable. Lancet 2004;364:1273-80. 
20. Davis PR. Rethinking the welfare regime approach: the case of Bangladesh. Global Soc Policy 2001;1:79-107.

21. White SC. NGOs, civil society, and the state in Bangladesh: the politics of representing the poor. Dev Change 1999;30:307-26.

22. Cornwall A, Gaventa J. From users and choosers to makers and shapers: repositioning participation in social policy. Brighton: Institute of Development Studies, 2001. 36 p. (IDS working paper no. 127).

23. Goetz AM, Gaventa J. Bringing citizen voice and client focus into service delivery. Brighton: Institute of Development Studies, 2001. 77 p. (IDS working paper no. 138).

24. Cockroft A, Andersson N, Milne D, Hossain MZ, Karim E. What did the public think of health services reform in Bangladesh? Three national community based surveys 1999-2003. Health Res Policy Syst 2007;5:1-7.

25. Mahmud S. Spaces for participation in health systems in rural Bangladesh: the experience of Stakeholder Community Groups, spaces for change? In: Cornwall AC, Coelho VS, editors. Spaces for change? The politics of citizen participation in new democratic arenas. London: Zed Publishers, 2007:55-75.

26. Schuler SR, Bates LM, Islam MK. Paying for reproductive health services in Bangladesh: intersections between cost, quality and culture. Health Policy Plann 2002;17:273-80.

27. White H. The Bangladesh health SWAP: experience of a new aid instrument in practice. Dev Policy Rev 2007;25:451-72.
28. Popay J, Escorel S, Hernández M, Johnston H, Mathieson J, Rispel L. Understanding and tackling social exclusion: final report to the WHO Commission on Social Determinants of Health from the Social Exclusion Knowledge Network. Geneva: World Health Organization, 2007. $207 \mathrm{p}$.

29. Education Watch. Literacy in Bangladesh: the need for a new vision. Dhaka: Campaign for Popular Education, 2002. 10 p.

30. Shiffman J, Wu Y. Norms in tension: democracy and efficiency in Bangladeshi health and population sector reform. Soc Sci Med 2003;57:1547-57.

31. Szreter S, Woolcock M. Health by association? Social capital, social theory, and the political economy of public health. Int J Epidemiol 2004;33:650-67.

32. Ghafur S. Entitlement to patrongage: social construction of household claims on slum improvement project, Bangladesh. Habitat Int 2000;24:261-78.

33. Ross GC. Sustaining menstrual regulation policy: a case study of the policy process in Bangladesh. London: University of London, 2002. 241 p.

34. Buse K, Gwin C. The World Bank and global cooperation in health: the case of Bangladesh. Lancet 1998;351:665-9.

35. Edwards M, Sen G. NGOs, social change and the transformation of human relationships: a 21st century civic agenda. Third World Q 2000;21:605-16.

36. Sen A. Development as freedom. New Delhi: Oxford University Press, 2000. 384 p. 